\title{
A Bibliometric Review of Technostress: Historical Roots, Evolution and Central Publications of a Growing Research Field
}

\author{
Julius-Viktor Grummeck-Braamt \\ The University of \\ Newcastle, Australia \\ juliusviktor.grummeckbraamt@, \\ $\underline{\text { uon.edu.au }}$
}

\author{
Ilja Nastjuk \\ University of Göttingen \\ ilja.nastjuk@wiwi.uni- \\ goettingen.de
}

\author{
Arash Najmaei \\ Australian Catholic \\ University \\ arash.najmaei@ \\ acu.edu.au
}

\author{
Marc T. P. Adam \\ The University of \\ Newcastle, Australia \\ marc.adam@ \\ newcastle.edu.au
}

\begin{abstract}
While previous research has provided critical insights into the different perspectives, methods, and theories on technostress, there is no bibliometric review available that clarifies the evolution and structure of the field. We use three bibliometric methods to assess the body of 252 technostress publications until 2019: reference publication year spectroscopy, co-word analysis, and co-citation analysis. In doing so, we analyze how the technostress field has evolved over time, clarify the interconnected concepts forming the discourse, and identify the most influential works.
\end{abstract}

\section{Introduction}

First coined in the 1980s [5], technostress is defined as a "a modern disease of adaptation caused by an inability to cope with new technologies in a healthy manner" (p. 16). It is characterized in two distinctive but interrelated processes - over-identification with technology and the struggle to accept technology [5]. While a primary aspect of over-identification with technology is a lack to interact and empathize with others, humans struggle to accept technology due to a variety of reasons (e.g. fear of making irreversible mistakes, perceived lack of skills) $[5,57]$. A range of technology-related demands such as complexity, overload, and constant connectivity can cause stress in individuals and lead to serious undesirable physical, psychological, and behavioral consequences including antisocial behavior, anxiety, depression, heart disease, headaches, and muscle cramps [29, 44, 45, 52].

While existing literature reviews on technostress provide important insights into the breadth of methods, perspectives, and theories underpinning technostress literature [15, 16, 29, 45, 52], Tarafdar et al. [52] note that there is a need for more studies that " articulate how the IS literatures on technostress and the non-IS literatures that study psychological stress can mutually enrich and inform one another" and that "it is necessary to understand the current theoretical expositions of technostress." (p. 2). To the best of our knowledge, there is currently no review available that provides a bibliometric assessment of technostress literature. Bibliometric analysis helps to understand a research field's composition, research concepts, influential authors, and interconnections [66]. In this vein, Zupic and Cater [66] emphasize that bibliometric reviews "are not a substitute for but a complement to traditional methods of review" (p. 436) and they can help to provide structure and guidance to a research field. Against this backdrop, and to complement the existing reviews on the technostress phenomenon, this paper sets out to address the following research question (RQ):

RQ: How has the field of technostress research evolved since its inception and what are the main conceptual ideas underpinning technostress?

Specifically, we use reference publication year spectroscopy (RPYS) to analyze the historical roots of technostress research [35], co-word analysis to map out the evolution of keywords [9], and co-citation analysis to identify central technostress publications [66]. In alignment with prior bibliometric reviews, we use the Scopus database (e.g. [20]). Assessing 252 publications published until 2019, we find that the historical roots of technostress are primarily based in psychology and biology and on quantitative methods. Our results also show that technostress research has continuously grown to a closely connected network with 14 clusters and 138 keywords in 2019. Finally, this research sheds light on the ten most central technostress publications, published mainly in IS, marketing, and psychology journals.

Our study complements the rich body of existing literature reviews by introducing a novel method to assess the evolution and conceptual structure of technostress research. In addition, our study assists scholars in gaining a clear pathway about the importance and potential impact of emerging research directions [64]. The study also provides meaningful insights for practitioners by identifying the causes, underlying processes, outcomes, and trends of technostress which can support practitioners to address the challenges associated with this phenomenon. 


\section{Foundations on Technostress}

The transactional view of stress [31] has provided the theoretical foundation for technostress research in information systems (IS) literature (e.g. [44]). Lazarus and Folkman [31] define stress as "a particular relationship between the person and the environment that is appraised by the person as taxing or exceeding [their] resources and endangering [their] well-being." (p. 19). Aligned with this perspective, research has captured technostress through four complementary lenses: (1) technology environmental conditions, (2) cognitive appraisals, (3) coping responses, and (4) strain $[3,19,44,52]$.

Technology environmental conditions refer to characteristics of organizational technologies that have the potential to cause technostress by creating a demand in the individual $[3,44]$. First, ubiquitous technologies (e.g. mobile phones) enable constant connectivity. This can extend the regular workday and cause feelings of invasion to employees' private time and space because they can be reached anytime and everywhere. Second, interconnected technologies demand users to handle multiple streams of information from a variety of sources [44], which can cause information overload [28]. Third, the rapid advances in technologies creates competitive pressure for companies to catch up to the latest developments [44]. As a result, users may feel intimidated and forced to increasingly spend more time in understanding and using technologies [44, 62]. Fourth, rapidly changing technologies require businesses to frequently update and modify their technologies to align them with their business processes. Such circumstances exacerbate the individual's ability to establish experience with technologies and thus might result in technostress [44]. Fifth, technologies enable excessive multitasking to accomplish more tasks in less time. Consequently, users experience higher tensions, less control, and lower job satisfaction [44, 62]. Finally, work-related interruptions through technologies such as e-mail or instant messaging can hamper work productivity and thus trigger technostress [19].

Primary and secondary cognitive appraisal processes determine to what degree technological environmental conditions function as stressors [31]. As for primary appraisal, individuals evaluate and categorize conditions with respect to their well-being as either irrelevant, benign-positive, or stressful. Stressfulappraised conditions trigger the evaluation of available and relevant coping resources (secondary appraisal) to respond to stressful situations [13, 31]. Technostress emerges when the individual's coping resources are insufficient to manage situations appraised as stressful. Primary appraisal influences the relationship between technology environmental conditions and stressors, while secondary appraisal moderates the relationship between stressors and coping responses [52]. Based on these theoretical considerations, scholars distinguish five main techno-stressors: techno-insecurity, technoinvasion, techno-complexity techno-overload and techno-uncertainty [44, 54, 55].

According to Lazarus and Folkman [31] coping refers to "constantly changing cognitive and behavioral efforts to manage specific external and/ or internal demands that are appraised as taxing or exceeding the resources of the person" (p. 141). The coping process is dynamic and characterized by an individual's specific cognitive appraisal processes [31]. Technostress research distinguishes two major forms of coping: problem-focused and emotion-focused [52]. Problemfocused coping focuses on managing or altering the stress causing situation such as by extending individual skills or knowledge [31]. Emotion-focused coping alters thoughts and emotions about the stressful situation [31].

Referring to the outcome of technostress [55], research distinguishes physiological, psychological, and behavioral strain [3, 13, 44]. Psychological strain manifests in emotional reactions to stressors and includes, for example, dissatisfaction [55] or exhaustion [34]. Behavioral strain refers to behavioral technostress responses and encompasses, among others, decreased productivity, quitting a job, or non-compliance behavior $[44,52]$. Physiological strain is characterized by bodily responses and includes, for example, increased cardiovascular activity and cortisol levels [45].

\section{Method}

\subsection{Index Database}

Bibliometric assessments require an index database [33] and, therefore, not every academic database was eligible. While Scopus and Web of Science are the main databases for bibliometric analysis, it has been shown that Scopus yields a wider coverage and identification of citable articles than Web of Science, particularly in the field of IS $[12,38]$. Hence, we decided to conduct our search in Scopus (for a similar approach, see [20]).

As noted by Tarafdar et al. [52], technostress research is inherently interdisciplinary in nature and it is important to acknowledge that different disciplines (e.g. IS, psychology) use slightly different terms to investigate the phenomenon. Therefore, we followed the keywords selection of Tarafdar et al. [52]. For literature published in IS, we used: (techno AND stress) OR stress OR strain OR coping as keywords. To find publications outside to IS, we used: (techno OR ICT OR telework OR telecommut OR "e- mail" OR electronic OR "virtual work”) AND (stress OR strain OR coping). 
To consider full years of research activity, our research is delimited to the end of 2019. The initial search yielded 1033 publications published between 1982 and 2019. We excluded editorials, letters, and book reviews since they are not considered as citable items in bibliometric reviews [33], leaving 1023 records for title and abstract screening. In the screening, we only retained publications that are related to technostress with focus on techno-stressors, coping responses, technology environmental conditions, outcomes, and moderators of the stressor-outcome relationship. In order to ensure reliability of our selection process, two authors separately assessed the records and resolved disagreements using a consensus approach [42]. After removing 771 records, we arrived at a final sample of 252 articles. The sample size emphasizes one advantage of bibliometric assessments as they allow authors to evaluate a high number of academic records by applying a quantitative approach [66]. This becomes evident by comparing our sample size to other existing technostress reviews which assessed between 15 and 105 studies (e.g. $[15,16,29,52])$.

\subsection{Reference Publication Year Spectroscopy}

To provide insights into the historical science background of technostress research, we used RPYS analysis following Hou [22]. RPYS allows to detect a field's historical origins and to quantify their citation impact on contemporary research outputs [35]. Marx et al. [35] emphasized that "the content of an earlier publication and that of the later publication are related and that the former is of significance to the knowledge claim in the latter" (p. 752). In this regard, there is generally a positive relationship between the frequency of a cited work and the impact on the advancement of knowledge. Further, more frequently cited publications lean on previously highly cited research outputs [35]. Thus, the relationship between current research and past literature assists in quantifying the impact of certain concepts, theories, and methods on the development of knowledge within a given field [22, 35].

We used CRExplorer (http://crexplorer.net) to perform the RPYS analysis. We extracted all references with CRExplorer to identify the publication year of the most important documents in technostress. Then we removed duplicates and harmonized varieties of references. Finally, we determined the distribution of literature with the highest citation frequency in technostress research. As suggested by Marx et al. [35], we used a 5-year (i.e. Y-2, Y-1, Year of publication,

\footnotetext{
${ }^{1} \mathrm{Su}$ and Lee [49] argue that "it is better not to modify the concept of keywords defined and selected by the authors since this will avoid unnecessary debates" (p. 69).
}

$\mathrm{Y}+1, \mathrm{Y}+2)$ deviation from the median of citations and a minimum citation count of 10 to identify the historical roots of technostress research.

\subsection{Co-word Analysis}

Co-word analysis examines patterns of cooccurrences of pairs of items (e.g. keywords) to identify interrelated research concepts [9]. By representing research concepts, keywords are suitable to reveal the knowledge structure and its development within a particular field [49]. Following the advice of Su and Lee [49], we did not modify concepts of keywords. ${ }^{1}$ However, it is necessary to standardize certain keywords because different keywords can be used to describe the same concept such as "technostress" and "techno-stress". Based on this approach, every standardized keyword represents a unique concept [49].

Keywords co-occur if they appear in the same citation context. The distance between two keywords is proportional to the relatedness of the keywords $[49,66]$. Building on this co-occurrence, one can construct a network map that represents the conceptual space of a research field [66]. Keyword maps produced for consecutive time periods can help to comprehend the development of such concepts [26]. To visualize the evolution of major keyword clusters [43] whilst also displaying emerging topics, we considered all keywords that were mentioned at least twice [26].

We used VOSviewer (http://vosviewer.com) to perform the co-word analysis. It performs bibliometric analysis using the so-called Visualization of Similarities (VOS) technique and offers access to the VOS mapping technique. VOS is a mapping technique that serves as an alternative to the traditional multidimensional scaling (MDS). We chose VOSviewer because it provides a more satisfactory representation of a dataset than the traditional MDS approach which facilitates graphical interpretation [61]. VOSviewer clusters the keywords based on their co-occurrence [61].

\subsection{Co-citation Analysis}

To identify the most central technostress publications, we conducted a co-citation analysis [66]. Co-citation analysis establishes the similarity between publications, authors, or journals by determining cocitation counts [66]. Co-citation means that two documents are cited when they are listed in a citing item's reference list. The basic assumption of cocitation analysis is that the more frequently two items 
are co-cited, the more closely they are linked together and the more likely they are assigned to one cluster [43, 66]. We used a document co-citation analysis to connect the published documents within technostress research which allows us to identify the most important works [66]. Following Raghuram et al. [43], we started with a co-citation threshold of 15 citations which we then gradually lowered to eight citations. This accounts for the fact that technostress is still a young research field [52]. We used VOSviewer to perform the co-citation analysis (http://vosviewer.com).

\section{Results}

\subsection{Results of RPYS}

Figure 1 shows the 5-year-median deviation curve [22]. Capturing the evolution of the knowledge structure over time [22], it reveals a total of 20 citation peaks between 1950 and 2019, with the four most prominent peaks in 1984, 2007, 2011, and 2015.

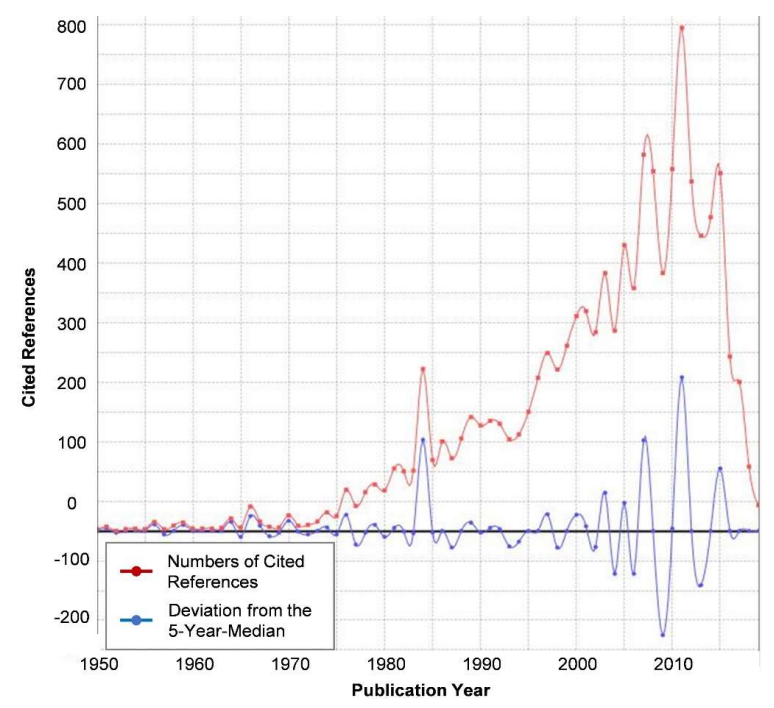

Figure 1. Evolution of Technostress Research

Table 1 provides an overview of the 20 citation peaks, the outlets and areas. It shows that while early research was mainly based in biology and psychology, more recent citation peaks are primarily in the IS area. Each peak is a highly cited publication that impacts current research outputs.

Between 1950 and 1983 we could identify works which are fundamental for technostress research but do not address technostress directly. Nine publications investigate stress from a biological and psychological points of view. Several methodological works set the foundations for later research. Establishing the biological perspective, Selye [47] introduced the notion of homeostasis or general adaptation syndrome. Later work frequently refers to Selye [47] to discuss the physiology of technostress and to distinguish eustress and distress (e.g. [45, 52]). In terms of quantitative methods, the work by Campbell and Fiske [10] and Fornell and Larcker [17] emerged as highly influential articles. The Transactional Theory of Stress by Lazarus [30] and McGrath [36] are two works which act as critical theoretical foundations in technostress research.

Table 1: Top 20 Citation Peaks

\begin{tabular}{|l|l|l|}
\hline$\#$ & \multicolumn{1}{|c|}{ Authors (Year) } & \multicolumn{1}{c|}{ Outlet [Area] } \\
\hline 1 & Selye (1956) [47] & Monography [BIO] \\
\hline 2 & Campbell \& Fiske (1959) [10] & Psych. Bulletin [PSY] \\
\hline 3 & Kahn et al. (1964) [24] & Monography [PSY] \\
\hline 4 & Lazarus (1966) [30] & Monography [PSY] \\
\hline 5 & Rizzo et al. (1970) [46] & Admin. Sci. Quart. [MAN] \\
\hline 6 & Selye (1976) [48] & Monography [BIO] \\
\hline 7 & McGrath (1976) [36] & Handbook [PSY] \\
\hline 8 & Karasek (1979) [25] & Admin. Sci. Quart. [MAN] \\
\hline 9 & Fornell \& Larcker (1981) [17] & J. Mkt. Res. [MKT] \\
\hline 10 & Brod (1984) [5] & Monography [IM//PSY] \\
\hline 11 & Carver et al. (1989) [11] & J. Pers. Soc. Psych. [PSY] \\
\hline 12 & Aiken (1991) [2] & Monography [SOC] \\
\hline 13 & Kupersmith (1992) [28] & Reference Serv. Rev. [SOC] \\
\hline 14 & Weil \& Rosen (1997) [62] & Monography [IM/PSY] \\
\hline 15 & Moore (2000) [39] & MIS Quart. [IM] \\
\hline 16 & Podsakoff et al. (2003) [41] & J. Appl. Psych. [PSY] \\
\hline 17 & Tu et al. (2005) [57] & Commun. ACM [IM] \\
\hline 18 & Tarafdar et al. (2007) [54] & J. Manag. Inf. Sys. [IM] \\
\hline 19 & Ayyagari et al. (2011) [3] & MIS Quart. [IM] \\
\hline 20 & Maier et al. (2015) [34] & Inf. Sys. J. [IM] \\
\hline
\end{tabular}

Note: Studies are listed in chronological order, with outlets categorized by subject areas (based on ABS 2018 Guide and SCImago Rank). We categorize books based on their key topics. BIO = Biology, $I M=$ Information Management, $M A N=$ Management, $P S Y=$ Psychology, SOC = Social Sciences.

Brod [5] in 1984 coined the term technostress and resulted in one of the main citation peaks. The peaks of Aiken [2] in 1991 and Podsakoff et al. [41] in 2003 emphasize that the importance of quantitative methods continued to grow. Also, the psychological perspective continued to be a major focus with a particular emphasis on the organizational context (e.g. [11, 39]). As such, main citation peaks discuss the phenomenon from an organizational point of view [28, 57]. The work of Tarafdar et al. [54] in 2007 introduced the concept of technostress in leading IS outlets [52]. Another major citation peak in 2011 is the work of Ayyagari et al. [3]. The authors used the person-environment fit model to clarify the relationship between technology characteristics, and stress within organizations. Finally, the most recent citation peak is marked by the work of Maier at al. [34], who expanded technostress research to the private context of social media. 


\subsection{Results of Co-word Analysis}

To determine the evolution of the knowledge structure, we created three snapshots (see Figure 2) that align with major citation peaks identified in our RPYS analysis $(2007,2015)$ and the end of the review period (2019). Each snapshot refers to the cumulative technostress literature up to that point in time.

a) Snapshot 1 (2007)

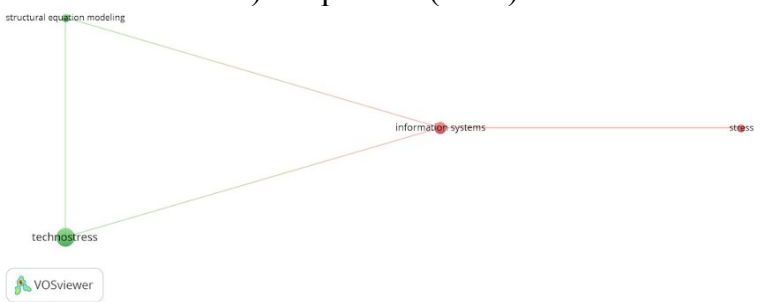

b) Snapshot 2 (2015)

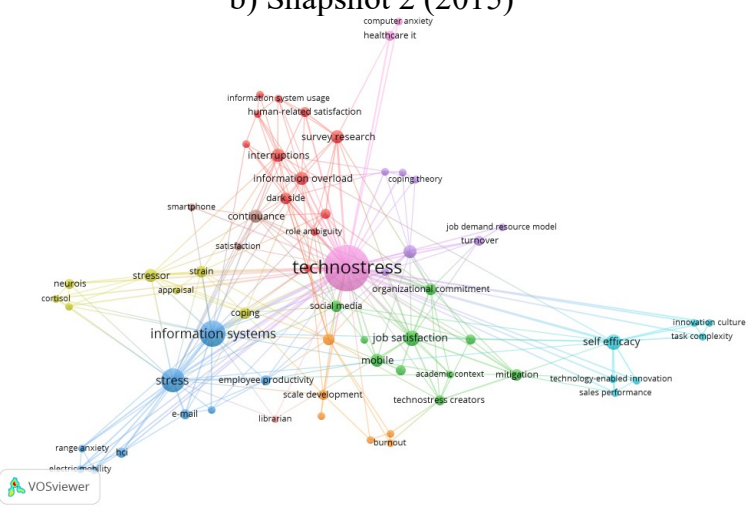

c) Snapshot 3 (2019)

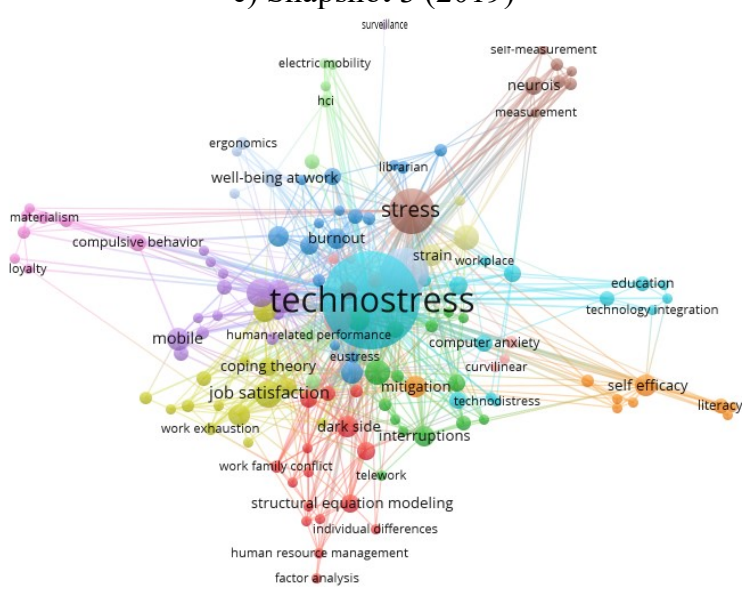

s vosiener

Figure 2. Results of Co-word Analysis

Note: Size of bubbles indicates importance of keywords. Thickness of lines shows the strength of keyword co-occurrence.

Figure 2 shows that technostress is a continuously growing field that evolved from 2 connected clusters until 2007 (4 keywords), to a network of 10 clusters in
2015 (65 keywords), and finally a network of 14 clusters in 2019 (138 keywords). The three snapshots are described in the following.

Snapshot 1 (2007). The keywords are related to the phenomenon of technostress itself (technostress, information systems, and stress) and methodological aspects (structural equation modeling) that emphasize how scholars conceptualized the phenomenon by means of quantitative studies. Early studies emerged in the fields of IS and psychology and mainly focused on cognitive appraisal processes, coping responses, and strain to characterize technostress $[5,28,54,57,62]$. Two of these studies $[54,57]$ use quantitative methods.

Snapshot 2 (2015). A variety of additional concepts emerge, including creators (e.g. stressor, interruptions), outcomes (e.g., job satisfaction, burnout, sales performance, turnover, continuance), theoretical foundations (e.g., transactional theory, job demand resource model, coping theory), individual beliefs (e.g., self-efficacy), inhibiting mechanisms (e.g., mitigation), and application contexts (e.g. smartphone, electric mobility). In addition, while many studies rely on surveys, the 2015 snapshot additionally exhibits an increased importance of the neurobiological perspective. For example, Riedl [45] and Tams et al. [50] emphasize that physiological measures (e.g. stress hormone levels) are essential to complement self-report measures and more comprehensively capture how individuals experience technostress.

Snapshot 3 (2019). Compared to 2015, the number of keywords $(65 \rightarrow 138)$ and clusters $(10 \rightarrow 14)$ further grew substantively. Thereby, we can see that the increase in keywords relates to additional application fields outside the organizational context, such as social media (e.g. [6]) and education (e.g. [63]). Another interesting keyword that emerged was individual differences. Research has shown that the experience of technostress is highly subjective to individual characteristics and personality traits, including age, agreeableness, computer confidence, education, experience, extraversion, gender, neuroticism, and technology self-efficacy [27, 44, 51, 53, 56].

Further, when comparing the top 10 keywords as shown in Table 2, we can see that two major differences arise between the 2015 and 2019 snapshots: the addition of social media and coping. This highlights not only the significance of regulation capabilities as a key concept in technostress but also the relevance of the private usage context. This is a shift compared to traditional technostress research that focused primarily on the organizational context (e.g. [54, 57]). However, the use and development of IS has changed dramatically in recent years as emphasized by McKenna et al. [37]: "Instead of being developed for (and used by) 
organizational "users", information systems are more and more being developed for consumers" (p. 248).

Finally, we see that the keyword dark side disappeared from the top 10 in the snapshot until 2019, indicating a change in perspective. In this context, Tarafdar et al. [52] concluded that the "overarching and exclusive premise of the literature regarding technostress is that of a phenomenon associated with negative consequences." (p.7). By contrast, recent research since 2015 emphasized a so-called "bright side" of technostress, which denotes a favorable appraisal of demands that may entail positive psychological outcomes $[7,8]$.

Table 2. Top 10 keywords until 2015 and 2019

\begin{tabular}{|c|l|l|c|c|c|c|}
\hline \multirow{2}{*}{$\#$} & \multicolumn{2}{|c|}{ Keywords } & \multicolumn{2}{c|}{ KTLS } & \multicolumn{2}{c|}{ Occurrences } \\
\cline { 2 - 7 } & \multicolumn{1}{|c|}{$\mathbf{2 0 1 5}$} & \multicolumn{2}{|c|}{2015} & $\mathbf{2 0 1 9}$ & $\mathbf{2 0 1 5}$ & $\mathbf{2 0 1 9}$ \\
\hline 1 & technostress & technostress & 141 & 435 & 60 & 157 \\
\hline 2 & inf. systems & stress & 47 & 122 & 20 & 34 \\
\hline 3 & stress & inf. systems & 45 & 112 & 16 & 38 \\
\hline 4 & job satisfaction & stressor & 24 & 46 & 7 & 11 \\
\hline 5 & self-efficacy & social media & 24 & 45 & 7 & 14 \\
\hline 6 & stressor & coping & 20 & 45 & 5 & 13 \\
\hline 7 & survey research & inf. sys. usage & 16 & 43 & 5 & 11 \\
\hline 8 & org. commitment & job satisfaction & 16 & 39 & 4 & 13 \\
\hline 9 & continuance & continuance & 16 & 37 & 5 & 9 \\
\hline 10 & dark side & org. commitment & 15 & 32 & 4 & 8 \\
\hline
\end{tabular}

Note: Keywords are sorted according to keyword total link strength (KTLS). Keyword total link strength quantifies the links one keyword has with all other keywords (calculated with VOSviewer).

\subsection{Results of Co-citation Analysis}

The co-citation analysis yields a network of 138 publications as visualized in Figure 3. Thereby, each document is assigned a total link strength that quantifies the links with all other documents. For instance, a high total link strength shows that a document has several strong links to a limited number of other documents or many weak links with a large number of other publications [23, 61].

Up until the end of 2019, the analysis reveals five co-citation clusters. Cluster 1 is the largest cluster and contains 44 references. The document with the highest weight in this cluster is Lazarus and Folkman's [31] work on the transactional theory of stress. Other central documents within this cluster also discuss the phenomenon of psychological stress (e.g. [30]). Cluster 2 includes 35 references, with the highest weight by the work of Ragu-Nathan et al. [44] on technostress in organizations. Similarly, Ayyagari et al. [3] and Tarafdar et al. [55] present important articles within this cluster that discuss technostress in an organizational context. Cluster 3 contains 29 documents (highest weight: Tarafdar et al. [54]). Interestingly, this cluster contains historically important articles as revealed by the RPYS (e.g. [2, 13, 47]). This highlights the relevance of the article of Tarafdar et al. [54] for technostress research [52]. Cluster 4 contains 27 documents, with the highest weight contributed by the 1984 monography by Brod [5] coining the term technostress. Similar central publications within this clusters are Kupersmith [28] and Weil and Rosen [62]. Lastly, Cluster 5 contains three articles (highest weight: Beaudry and Pinsonneault [4]). The articles discuss user adaption, information security policy compliance, and organizational stress.

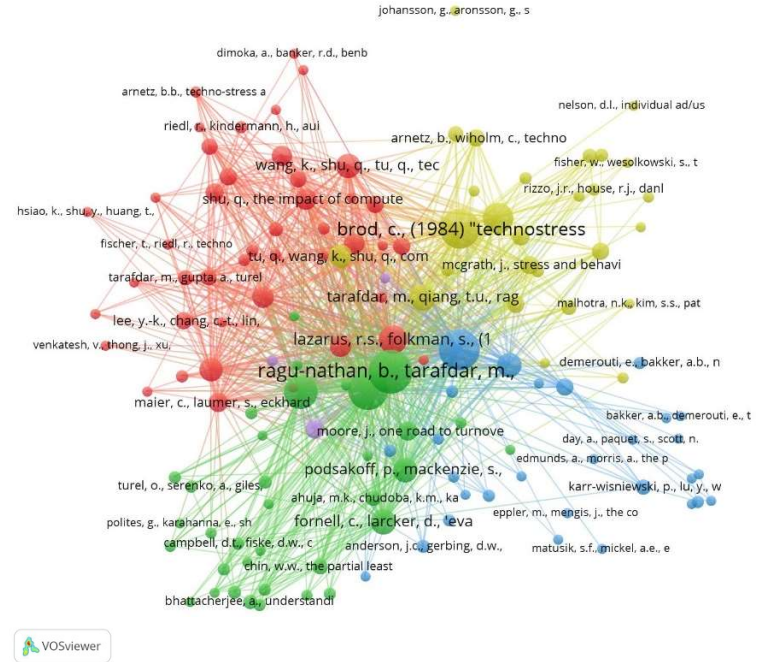

Figure 3. Results of Co-citation Analysis

Note: A document's label and bubble size reflect its weight. The proximity between bubbles indicates how closely related articles are.

Table 3 lists the 10 most central publications which influenced technostress research based on their total link strengths. This includes publications with inherent focus on technostress (e.g. [3, 44]) as well as papers not directly related to technostress such as method papers (e.g. $[17,41])$. It reveals that the top articles appeared in IS, marketing, and psychology journals and that they primarily employed the methods of surveys, literature reviews, and simulation analysis. Most documents discussed technostress in an organizational context. While two articles evaluated research methods [17, 41], one work discussed the underlying psychological processes of stress [31].

The co-citation analysis identifies Ragu-Nathan et al. [44] as the most central article influencing technostress research until 2019. The scholars developed and validated the technostress questionnaire in organizations. The study was published in 2008 when technostress research was still in its early stages. Since then, the questionnaire has been widely used (e.g. [18, 56]) which might be one contributing factor why technostress research is predominantly applied in an organizational context (e.g. [29, 45]). 
All journal articles within the top 10 which focus on technostress used the research method of surveys. This finding is reinforced by the fact that Fornell and Larcker [17] and Podsakoff et al. [41] represent central publications which influenced technostress research. Both articles focus on quantitative research methodologies and common method biases. This confirms that technostress research largely builds on quantitative data gathered through surveys $[15,52]$.

Table 3. Top 10 most central publications that influence technostress research

\begin{tabular}{|l|c|l|l|}
\hline \multicolumn{1}{|c|}{ Authors (Year) } & PTLS & Outlet [Area] & Method \\
\hline Ragu-Nathan et al. (2008) [44] & 2036 & $\begin{array}{l}\text { Inf. Sys. Res. } \\
{[\text { IM] }}\end{array}$ & survey \\
\hline Ayyagari et al. (2011) [3] & 1802 & $\begin{array}{l}\text { MIS Quart. } \\
{[\text { IM] }}\end{array}$ & survey \\
\hline Tarafdar et al. (2007) [54] & 1754 & $\begin{array}{l}\text { J. Manag. Inf. } \\
\text { Sys. [IM] }\end{array}$ & survey \\
\hline Tarafdar et al. (2010) [55] & 1405 & $\begin{array}{l}\text { J. Manag. Inf. } \\
\text { Sys. [IM] }\end{array}$ & survey \\
\hline Brod (1984) [5] & 1186 & $\begin{array}{l}\text { Monography } \\
\text { [IM/PSY] }\end{array}$ & lit. review \\
\hline Lazarus \& Folkman (1984) [31] & 987 & $\begin{array}{l}\text { Monography } \\
\text { [PSY] }\end{array}$ & lit. review \\
\hline Tarafdar et al. (2011) [56] & 889 & $\begin{array}{l}\text { Commun. } \\
\text { ACM [M] }\end{array}$ & survey \\
\hline Fornell \& Larcker (1981) [17] & 829 & $\begin{array}{l}\text { J. Mkt. Res. } \\
{[\text { MKT] }}\end{array}$ & simulation \\
\hline Weil \& Rosen (1997) [62] & 820 & $\begin{array}{l}\text { Monography } \\
{[\text { IM/PSY] }}\end{array}$ & lit. review \\
\hline Podsakoff et al. (2003) [41] & 797 & $\begin{array}{l}\text { J. Appl. } \\
\text { Psych. [PSY] }\end{array}$ & lit. review \\
\hline
\end{tabular}

Note: Publication total link strength (PTLS) quantifies a publication's links with all other publications considered in the analysis (calculated with VOSviewer). Publications are ordered by PTLS, with outlets categorized by subject areas (based on ABS 2018 Guide and SCImago Rank). We categorize books based on their key topics. $B I O=$ Biology, $I M=$ Information Management, $M A N=$ Management, $P S Y=$ Psychology, SOC = Social Sciences.

\section{Discussion}

Our analysis shows that technostress is a continuously growing field that has its historical roots in biology, psychology, and quantitative methods. The Transactional Theory of Stress [31] emerged as its central theoretical foundation (e.g. [44, 52, 57]). A majority of studies rely on quantitative methods (i.e. surveys) to explain and predict technostress (for a review see Fischer \& Riedl [16]). However, the emerging perspective of neurobiology [45] provides important complementary insights to broaden our understanding of how individuals experience technostress. While the majority of technostress research focuses on organizational technologies, we can observe a broadening of application areas in recent years, including healthcare IT (e.g. [7]), smartphone (e.g. [32]), electric mobility (e.g. [40]), social media (e.g. [34]), and education (e.g. [63]). Further, whereas earlier work has predominantly conceptualized technostress as an unintended negative consequence of technology usage (for a review see Tarafdar et al. [52]), a recent shift in focus shows that positive technostress appraisals (eustress) receive increasing research attention. Along this development, the keyword "dark side" appeared less frequently in recent years, while "coping" and "social media" appear more frequently.

Based on our findings, we identify three areas (techno-eustress, usage context, and research methodology) for future research as summarized in Table 4 which we discuss in the following.

Table 4. Area for future research

\begin{tabular}{|c|c|l|}
\hline$\#$ & Area & \multicolumn{1}{c|}{ Explanation } \\
\hline 1 & $\begin{array}{l}\text { Techno- } \\
\text { eustress }\end{array}$ & $\begin{array}{l}\text { Techno-eustress presents the positive side of } \\
\text { stress that individuals experience while using IS. } \\
\text { Techno-eustress in context of (1) technology } \\
\text { environmental conditions, (2) appraisal processes, } \\
\text { (3) coping responses, and (4) outcomes presents } \\
\text { fruitful research opportunities. }\end{array}$ \\
\hline 2 & $\begin{array}{l}\text { While historically technostress research } \\
\text { predominantly considered organizational } \\
\text { contexts, emerging application fields (e.g. } \\
\text { education, mobility, social media) call for a } \\
\text { broadened perspective on hedonic and utilitarian } \\
\text { usage in the private context, as well as their } \\
\text { intersection (e.g. work-from-home arrangements). }\end{array}$ \\
\hline 3 & $\begin{array}{l}\text { Technostress research relies predominantly on } \\
\text { quantitative surveys which in turn creates the } \\
\text { potential for complementary methodological } \\
\text { methodology } \\
\text { approaches (e.g. bibliometric assessments, design } \\
\text { science research, physiological measurements). }\end{array}$ \\
\hline
\end{tabular}

Techno-eustress. Recent studies expanded our understanding of the phenomenon of technostress by incorporating a so-called bright side, namely technoeustress (e.g. [7, 8]). This finding of our review aligns with Tarafdar et al. [52], noting that techno-eustress "introduces a new theoretical aspect to the phenomenon of technostress by considering its positive aspects and outcomes" (p. 25). As a positive affective state, technoeustress differs from techno-distress in terms of the underlying coping and appraisal processes. In this regard, users may evaluate their interaction with IS as challenging and apply coping processes towards positive outcomes [7]. From a conceptual perspective, eustress or techno-eustress respectively can be captured through four complementary lenses: (1) technology environmental conditions, (2) appraisal processes, (3) coping responses, and (4) outcomes [7, 36], each of which raising important aspects for future research.

First, future research should broaden the understanding of technology environmental conditions (e.g. IS design) in relation to techno-eustress. Stressors are inherently neutral which means that individuals might appraise a stressor differently [21]. Thus, an individual-focused research approach appears beneficial in order to understand this interplay further [7, 13]. 
Second, during the appraisal process the individual decides if a stressor is positive or negative [21]. This process is strongly impacted by individual differences $[21,36]$. Consequently, a further understanding of the appraisal process and the role of individual differences in relation to techno-eustress is a vital area for future research. Third, as coping responses can appear in different forms future research should investigate how individuals can cope with techno-distress and savor techno-eustress [7]. This is particularly relevant in relation to organizational outcomes as studies which investigate this relationship are limited [52]. Finally, understanding the relationship between techno-eustress and organizational outcomes so that "intended and unintended outcomes can be anticipated by managers" ([7], p. 811) would complement earlier work on the negative aspects of technostress and hence present a fruitful avenue for future research (e.g. [7, 8, 65]). This more nuanced approach is important to understand the holistic stress process in the context of IS [7, 52].

Usage context. Since 2015, research has started to investigate technostress in a range of private contexts, including smartphones (e.g. [32]), mobility (e.g. [40]) and social media (e.g. [34]). For instance, users can experience social overload when using social networks [34]. A general increase in the development of IS for consumers increases the necessity for technostress research in this application field [37]. Contrary to IS usage in organizational contexts [16], IS usage in private contexts is largely voluntary (hedonic use [58]) and individuals can switch between technologies. Maier et al. [34] refer to this phenomenon as switching behavior or more precisely as switching-stress creators and switching-exhaustion, broadening the conceptual view of technostress in private as compared to organizational settings. Further, the rapid proliferation of work-fromhome arrangements (e.g. due to COVID-19 restrictions) poses new technological and organizational challenges [60]. Therefore, future research should investigate the underlying technostress assumptions and processes for different technologies and usage settings.

Research methodology. In line with the reviews by Tarafdar et al. [52] and Fischer and Riedl [15], our bibliometric analysis confirms that technostress research relies predominantly on quantitative surveys. Complementary methodological approaches can help researchers to expand the existing insights. For instance, neurobiological outcomes of technostress can be assessed through a range of physiological measurements such as adrenal cortical secretions, blood pressure, brain activity, galvanic skin response, or pupil dilation $[1,19$, $45,50]$. In addition, mixed-methods research provides "an opportunity to develop novel theoretical perspectives by combining the strengths of quantitative and qualitative methods" ([59], p. 436). In this regard,
Califf et al. [7] emphasize the necessity to utilize mixedmethods in technostress research to account for the different usage settings that make it difficult to draw significant insights from existing theories and approaches. Thus, future technostress research may leverage mixed-method designs to address confirmatory and exploratory research questions simultaneously, which, in turn, enables a more complete assessment of the technostress phenomenon across different usage contexts [59]. Finally, a design-oriented approach can be used to provide insights into how systems can be designed to reduce stress in human-computer interaction and aid users in their coping strategies [1].

With our bibliometric assessment, we contribute to extending the methodological discourse in technostress research. However, our study is also subject to limitations that create further avenues for future research. First, future bibliometric studies could explore other databases (e.g., Web of Science) to capture publications that are not captured by Scopus. A further limitation is that we only considered author keywords in the co-word analysis. However, not every piece of bibliographic data contains keywords [66]. Future studies may apply text mining methods (e.g. on abstracts or full texts) to expand the findings of our co-word analysis. In addition, researchers could apply additional bibliometric techniques (e.g. bibliographic coupling or life-cycle analysis) to shed additional light specifically on emerging developments in technostress research. Compared to co-citation analysis, bibliographic coupling does not rely on historically accumulated citations. In doing so, this method enables researchers to assess emerging fields by taking into account more recent publications that have not been cited yet [66] Finally, a bibliometric study provides an overview of a research field, but it cannot offer an in-depth understanding of a research field [43]. Future research could apply further review methods, such as a metaanalysis to assess the rich body of existing research and potential existing contradictions.

\section{References}

[1] M.T.P. Adam, H. Gimpel, A. Maedche, and R. Riedl, "Design Blueprint for Stress-Sensitive Adaptive Enterprise Systems", Business and Information Systems Engineering 59(4), 2017, pp. 277-291.

[2] Aiken, L.S., S.G. West, and R.R. Reno, Multiple regression: testing and interpreting interactions, SAGE Publications Inc., Newbury Park Calif, 1991.

[3] R. Ayyagari, V. Grover and R. Purvis, "Technostress: technological antecedents and implications", MIS Quarterly 35(4), 2011, pp. 831-858.

[4] A. Beaudry, and A. Pinsonneault, "Understanding user responses to information technology: A coping model of 
user adaptation”, MIS Quarterly 29(3), 2005, pp. 493524.

[5] Brod, C., Technostress: The human cost of the computer revolution, Reading, MA: Addison-Wesley, 1984.

[6] S. Brooks, P. Longstreet, and C. Califf, "Social media induced technostress and its impact on Internet addiction: A distraction-conflict theory perspective", AIS Transactions on Human-Computer Interaction 9(2), 2017, pp. 99-122.

[7] C. Califf, S. Sarker, and S. Sarker, "The Bright and Dark Sides of Technostress: A Mixed-Methods Study Involving Healthcare IT.”, MIS Quarterly 44(2), 2020, pp. 809-856.

[8] C. Califf, S. Sarker, S. Sarker, and C. Fitzgerald, "The Bright and Dark Sides of Technostress: An Empirical Study of Healthcare Workers", ICIS, (2015), pp. 1-13.

[9] M. Callon, J.P. Courtial, W.A. Turner, and S. Bauin, "From translations to problematic networks: An introduction to co-word analysis", Social Science Information 22(2), 1983, pp. 191-235.

[10] D.T. Campbell and D.W. Fiske, "Convergent and discriminant validation by the multitrait-multimethod matrix”, Psychological Bulletin 56(2), 1959, pp. 81-105.

[11] C.S. Carver, M.F. Scheier, and K.J. Weintraub, "Assessing Coping Strategies: A Theoretically Based Approach", Journal of Personality and Social Psychology 56(2), 1989, pp. 267-283.

[12] A. Cavacini, "What is the best database for computer science journal articles?", Scientometrics 102(3), 2015, pp. 2059-2071.

[13] Cooper, C., C. Cooper, P. Dewe, and M. O'Driscoll, Organizational stress: A review and critique of theory, research, and applications, SAGE, 2001.

[14] J. D'Arcy, T. Herath, and M.K. Shoss, "Understanding Employee Responses to Stressful Information Security Requirements: A Coping Perspective", Journal of Management Information Systems 31(2), 2014, pp. 285318.

[15] T. Fischer and Riedl, R., "The status quo of neurophysiology in organizational technostress research: a review of studies published from 1978 to 2015", Information Systems and Neuroscience 10, 2015, pp. 917.

[16] T. Fischer and R. Riedl, "Technostress research: a nurturing ground for measurement pluralism?", Communications of the Association for Information systems 40(1), 2017, pp. 375-401.

[17] C. Fornell and D.F. Larcker, "Evaluating structural model with unobserved variables and measurement errors", Journal of Marketing Research 18(1), 1981, pp. 39-50.

[18] A.M. Fuglseth and $\varnothing$. Sørebø, "The effects of technostress within the context of employee use of ICT", Computers in Human Behavior 40, 2014, pp. 161-170.

[19] P.S. Galluch, Grover, V., and Thatcher, J.B., "Interrupting the Workplace: Examining Stressors in an Information Technology Context", Journal of the Association for Information Systems 16(1), 2015, pp. 147.

[20] N. Gerdsri, A. Kongthon, and R.S. Vatananan, "Mapping the knowledge evolution and professional network in the field of technology roadmapping: A bibliometric analysis", Technology Analysis and Strategic Management 25(4), 2013, pp. 403-422.

[21] M.B. Hargrove, D.L. Nelson, and C.L. Cooper, "Generating eustress by challenging employees", Organizational Dynamics 42(1), 2013, pp. 61-69.

[22] J. Hou, "Exploration into the evolution and historical roots of citation analysis by referenced publication year spectroscopy", Scientometrics 110(3), 2017, pp. 14371452.

[23] N. J. van Eck and L. Waltman, "Software survey: VOSviewer, a computer program for bibliometric mapping”, Scientometrics 84(2), 2009, pp. 523-538.

[24] Kahn, R., D. Wolfe, R. Quinn, and J. Snoek, Organizational stress: Studies in role conflict and ambiguity., John Wiley, 1964.

[25] R.A. Karasek, "Job Demands, Job Decision Latitude, and Mental Strain: Implications for Job Redesign", Administrative Science Quarterly 24(2), 1979, pp. 285308.

[26] P. Kokol and H.V. Outlook, "Historical, descriptive and exploratory analysis of application of bibliometrics in nursing research", Nursing Outlook 67(6), 2019, pp. 680-695.

[27] S. Krishnan, "Personality and espoused cultural differences in technostress creators", Computers in Human Behavior 66, 2017, pp. 154-167.

[28] J. Kupersmith, "Technostress and the reference librarian", Reference Services Review 20, 1992, pp. 7-50.

[29] G. LaTorre, A. Esposito, I. Sciarra, and M. Chiappetta, "Definition, symptoms and risk of techno-stress: a systematic review", International Archives of Occupational and Environmental Health 92(1), 2018, pp. 13-35.

[30] Lazarus, R., Psychological stress and the coping process., McGraw-Hill, 1966.

[31] Lazarus, R.S., and S. Folkman, Stress, Appraisal, And Coping, Springer Publishing Company, 1984.

[32] Y. Lee, C. Chang, Y. Lin, and Z. Cheng, "The dark side of smartphone usage: Psychological traits, compulsive behavior and technostress", Computers in Human Behavior 31, 2014, pp. 373-383.

[33] P.B. Lowry, G.D. Moody, J. Gaskin, et al., "Evaluating journal quality and the association for information systems senior scholars' journal basket via bibliometric measures: Do expert journal assessments add value?", MIS Quarterly 37(4), 2013, pp. 993-1012.

[34] C. Maier, S. Laumer, C. Weinert, and T. Weitzel, "The effects of technostress and switching stress on discontinued use of social networking services: A study of Facebook use", Information Systems Journal 25(3), 2015, pp. 275-308

[35] W. Marx, L. Bornmann, A. Barth, and L. Leydesdorff, "Detecting the historical roots of research fields by reference publication year spectroscopy (RPYS)", Journal of the Association for Information Science and Technology 65(4), 2014, pp. 751-764.

[36] McGrath, J.E., "Stress and behavior in organizations", In Handbook of Industrial and Organizational Psychology. Holt, Rinehart, \& Winston, 1976, pp. 1353-1395. 
[37] B. Mckenna, T. Tuunanen, and L. Gardner, "Consumers' adoption of information services", Information \& Management 50(5), 2013, pp. 248-257.

[38] L.I. Meho, and Y. Rogers, "Citation counting, citation ranking, and h-index of human-computer interaction researchers: A comparison of scopus and web of science", Journal of the American Society for Information Science and Technology 59(11), 2008, pp. 1711-1726.

[39] J.E. Moore, "One road to turnover: An examination of work exhaustion in technology professionals", MIS Quarterly 24(1), 2000, pp. 141-168.

[40] I. Nastjuk and L. Kolbe, "On the Duality of Stress in Information Systems Research-The Case of Electric Vehicles", ICIS, (2015), pp. 1-22.

[41] P.M. Podsakoff, S.B. MacKenzie, J.-Y. Lee, and N.P. Podsakoff, "Common method biases in behavioral research: a critical review of the literature and recommended remedies", Journal of Applied Psychology 88(5), 2003, pp. 879-903.

[42] H. Qahri-Saremi and A.R. Montazemi, "Factors Affecting the Adoption of an Electronic Word of Mouth Message: A Meta-Analysis", Journal of Management Information Systems 36(3), 2019, pp. 969-1001.

[43] S. Raghuram, P. Tuertscher, and R. Garud, "Mapping the field of virtual work: A cocitation analysis", Information Systems Research 21(4), 2010, pp. 983-999.

[44] T. S. Ragu-Nathan, Tarafdar, M., Ragu-Nathan, B. S., \& $\mathrm{Tu}, \mathrm{Q}$., "The consequences of technostress for end users in organizations: conceptual development and empirical validation”, Information Systems Research 19(4), 2008, pp. 417-433.

[45] R. Riedl, "On the biology of technostress: Literature review and research agenda", Data Base for Advances in Information Systems 44(1), 2013, pp. 18-55.

[46] J.R. Rizzo, R.J. House, and S.I. Lirtzman, "Role Conflict and Ambiguity in Complex Organizations", Administrative Science Quarterly 15(2), 1970, pp. 150163.

[47] Selye, H., The Stress of Life, McGraw-Hill Book Company, 1956.

[48] Selye, H., "Stress without Distress BT - Psychopathology of Human Adaptation", In Serban G. (eds). Psychopathology of Human Adaptation. 1976, pp. 137146.

[49] H.N. Su and P.C. Lee, "Mapping knowledge structure by keyword co-occurrence: A first look at journal papers in Technology Foresight", Scientometrics 85(1), 2010, pp. 65-79.

[50] S. Tams, J. Thatcher, K. Hill, V. Grover, and A.O. De Guinea, "NeuroIS-alternative or complement to existing methods? illustrating the holistic effects of neuroscience and self-reported data in the context of technostress research", Journal of the Association for Information Systems 15, 2014, pp. 723-753.

[51] S. Tams, J.B. Thatcher, and V. Grover, "Concentration, competence, confidence, and capture: An experimental study of age, interruption-based technostress, and task performance", Journal of the Association for Information Systems 19(9), 2018, pp. 857-908.
[52] M. Tarafdar, C.L. Cooper, and J.F. Stich, "The technostress trifecta - techno eustress, techno distress and design: Theoretical directions and an agenda for research", Information Systems Journal 29(6), 2017, pp. 6-42.

[53] M. Tarafdar, E.B. Pullins, and T.S. Ragu-Nathan, "Technostress: Negative effect on performance and possible mitigations", Information Systems Journal 25(2), 2015, pp. 103-132.

[54] M. Tarafdar, Q. Tu, B.S. Ragu-Nathan, and T.S. RaguNathan, "The impact of technostress on role stress and productivity", Journal of Management Information Systems 24(1), 2007, pp. 301-328.

[55] M. Tarafdar, Q. Tu, and T. Ragu-Nathan, "Impact of technostress on end-user satisfaction and performance", Journal of Management Information Systems 27(3), 2010, pp. 303-334.

[56] M. Tarafdar, Q. Tu, T.S. Ragu-Nathan, and B.S. RaguNathan, "Crossing to the dark side: Examining creators, outcomes, and inhibitors of technostress", Communications of the ACM 54(9), 2011, pp. 113-120.

[57] Q. Tu, K. Wang, and Q. Shu, "Computer-related technostress in China", Communications of the ACM 48(4), 2005, pp. 77-81.

[58] O. Turel, "Quitting the use of a habituated hedonic information system: A theoretical model and empirical examination of Facebook users", European Journal of Information Systems 24(4), 2015, pp. 431-446.

[59] V. Venkatesh, S.A. Brown, and Y.W. Sullivan, "Guidelines for conducting mixed-methods research: An extension and illustration", Journal of the Association for Information Systems 17(7), 2016, pp. 435-495.

[60] L. Waizenegger, B. McKenna, W. Cai, and T. Bendz, “An affordance perspective of team collaboration and enforced working from home during COVID-19", European Journal of Information Systems, 2020, pp. 114.

[61] L. Waltman, N. J. Van Eck, and E.C.M. Noyons, "A unified approach to mapping and clustering of bibliometric networks", Journal of Informetrics 4(4), 2010, pp. 629-635.

[62] Weil, M., and L. Rosen, Technostress: Coping with technology@work@home@play, Wiley, 1997.

[63] R.-J. Yang, J.-Y. Yang, H.-R. Yuan, and J.-T. Li, "Techno-Stress of Teachers: An Empirical Investigation from China", DEStech Transactions on Social Science, Education and Human Science, (2017), pp. 603-608.

[64] S. M. Zanjirchi, Abrishami, M. R., \& Jalilian, N., "Four decades of fuzzy sets theory in operations management: application of life-cycle, bibliometrics and content analysis", Scientometrics 119(3), 2019, pp. 1289-1309.

[65] X. Zhao, Q. Xia, and W. Huang, "Impact of technostress on productivity from the theoretical perspective of appraisal and coping processes", Information \& Management, 2020, pp. 1-11.

[66] I. Zupic, and T. Čater, "Bibliometric Methods in Management and Organization", Organizational Research Methods 18(3), 2015, pp. 429-472. 